\title{
Collagenase Nanoparticles Enhance the Penetration of Drugs into Pancreatic Tumors
}

Assaf Zinger ${ }^{1,8}$, Lilach Koren ${ }^{1,8}$, Omer Adir ${ }^{1}$, Maria Poley ${ }^{1}$, Mohammed Alyan ${ }^{1}$, Zvi Yaari ${ }^{1}$, Nadav

Noor ${ }^{6}$, Nitzan Krinsky ${ }^{1}$, Assaf Simon ${ }^{1}$, Hadas Gibori ${ }^{2}$, Majd Krayem ${ }^{1}$, Yelena Mumblat ${ }^{1}$, Shira

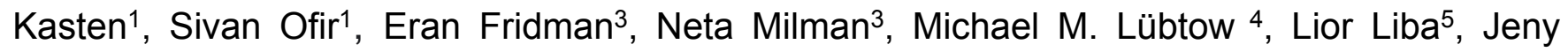

Shklover ${ }^{1}$, Janna Shainsky-Roitman ${ }^{1}$, Yoav Binenbaum ${ }^{3}$, Dov Hershkovitz ${ }^{7}$, Ziv Gil ${ }^{3}$, Tal Dvir ${ }^{6}$, Robert Luxenhofer ${ }^{4}$, Ronit Satchi-Fainaro ${ }^{2}$ and Avi Schroeder ${ }^{1, *}$

${ }^{1}$ Laboratory for Targeted Drug Delivery and Personalized Medicine Technologies, Department of Chemical Engineering, Technion - Israel Institute of Technology, Haifa 3200003, Israel 2Department of Physiology and Pharmacology, Sackler Faculty of Medicine, Tel Aviv University, Tel Aviv 6997800, Israel

${ }^{3}$ Department of Otolaryngology Head and Neck Surgery, Rambam Healthcare Campus, Technion-Israel Institute of Technology, Haifa 3200000, Israel

${ }^{4}$ Functional Polymer Materials, Lehrstuhl für Chemische Technologie der Materialsynthese, Julius-Maximilians-Universität Würzburg, Röntgenring 11, Würzburg 97070, Germany

${ }^{5}$ The Ruth and Bruce Rappaport Faculty of Medicine, Technion - Israel Institute of Technology, Haifa 3200003, Israel

${ }^{6}$ The School for Molecular Cell Biology and Biotechnology and the Department of Materials Science and Engineering, Tel Aviv University, Tel Aviv 6997800, Israel.

${ }^{7}$ Department of Pathology, Tel-Aviv Sourasky Medical Center, Sackler Faculty of Medicine, TelAviv University, Tel Aviv 6997800, Israel

8 These authors contributed equally to this work

*Corresponding author E-mail: (AS) avids@technion.ac.il 
A

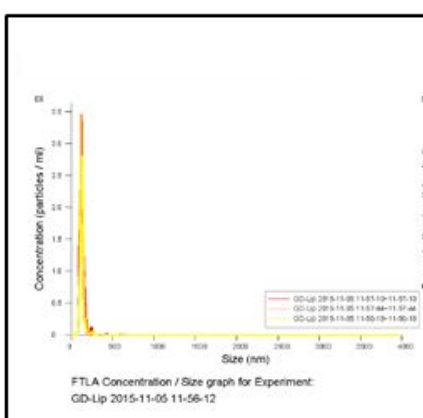

Inctuded fllos

GD.LP 2015:11.05 11.57.40

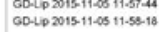

ontalls

NTA version

NTA Vervon.
Scriot Used:

Time Capbur

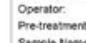

Sample Rimem-
Oluest:

Rement

Copture sortings

Camera Type:
Camera Levet:

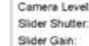

FPS

Number of Fin
Temperature
Vycoster

Viseovaly

Syringe Aump Speed.

Andyes Sortinges

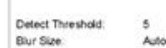

MTA3: BuId 31.46

Sop sondord Messi

11 s. 12 OST 1720

Asure Zinger

OD. 10 p $100 \mathrm{am}$
$1.0 \% \mathrm{in}$ PBS

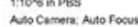

Asos

15
1206
366

366
25.0

7490

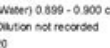

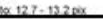

(2)

D-Lip 2015-11-05 11-56-12

1:

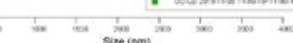

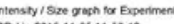

Sccipt Used: : Ful Toxil:

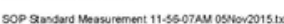

\section{B}

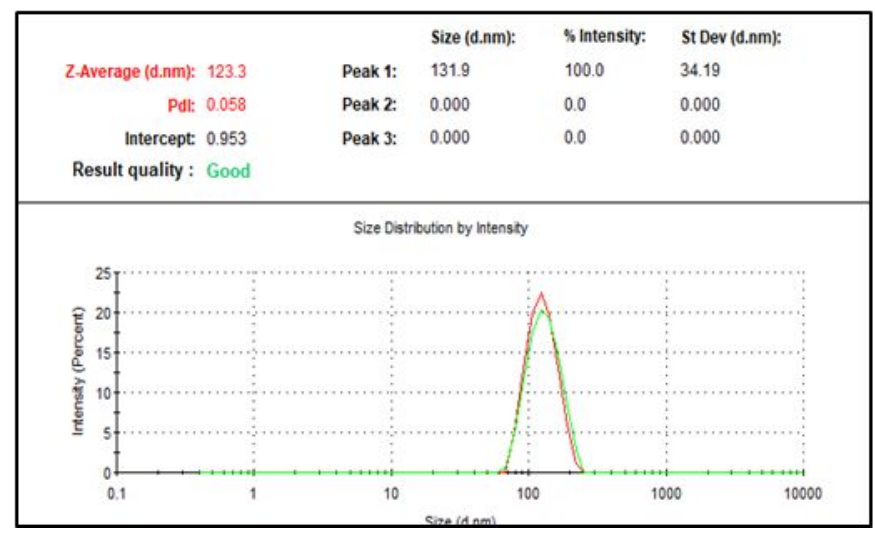

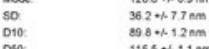

$\mathrm{C}$

\begin{tabular}{|c|c|c|c|c|}
\hline & & Mean $(\mathrm{mV})$ & Area (5) & St Dev $(\mathrm{mV}$ \\
\hline Zeta Potential (mV): -10.7 & Peak 1: & -8.45 & 87.6 & 6.06 \\
\hline Zeta Deviation (mV): 8.85 & Peak 2 : & -29.1 & 12.4 & 3.97 \\
\hline Conductivity (mS/cm): 1.09 & Peak 3: & 0.00 & 0.0 & 0.00 \\
\hline
\end{tabular}

Result quality : Good

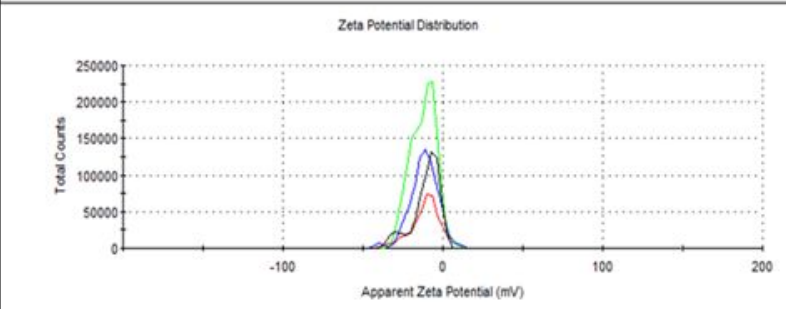$$
\text { Resulas }
$$

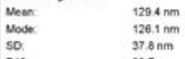

$\begin{array}{ll}097 \mathrm{~mm} \\ 010: & 1153 \mathrm{~nm} \\ 050: & 1452 \mathrm{~nm} \\ 050: & \end{array}$

Stess: Meen *t Standord Ener

$\begin{array}{ll}\text { Wean } & 129.4 *+24 \mathrm{~mm} \\ \text { Mode } & 126.6+1.9 .9 \mathrm{~mm} \\ \text { So } & 362 * 177 \mathrm{~mm}\end{array}$

$\begin{array}{ll}050 & 1155+1.1 .1 \mathrm{~mm} \\ 050 & 1430+1.45 \mathrm{~mm}\end{array}$

$1.31600000+23140007$ pertichent

$66,0+12$ sasticestame

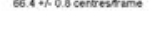

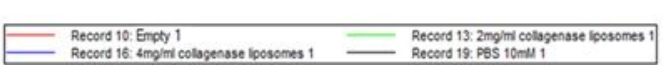

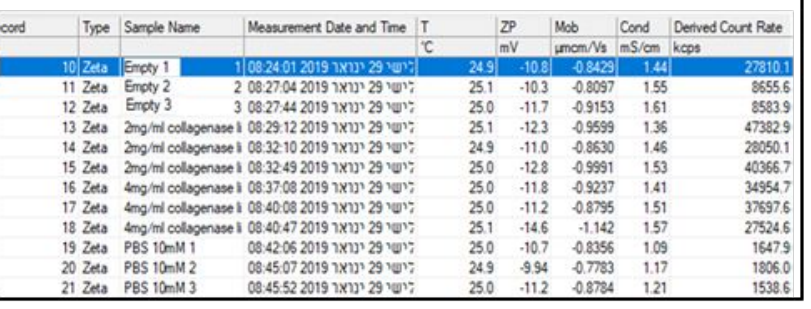

D

\begin{tabular}{|l|c|}
\hline & $\begin{array}{r}\text { 50mM lipids: } 56: 39: 5 \\
\text { DMPC: cholesterol :DSPE- } \\
\text { PEG2000 - 2mg/ml } \\
\text { collagenase }\end{array}$ \\
\hline $\begin{array}{l}\text { Concentration (mole/liter) of lipids } \\
\text { according to Stewart assay }\end{array}$ & 0.058 \\
\hline Concentration of lipids (gr/liter or mg/ml) & 38.87 \\
\hline $\begin{array}{l}\text { Flourescamine results for protein quantity } \\
\text { (mg) }\end{array}$ & 0.344 \\
\hline $\begin{array}{l}\text { Drug to lipid ratio according to } \\
\text { Fluorescamine }\end{array}$ & 0.0088 \\
\hline $\begin{array}{l}\text { Active protein based on Enzcheck (mg) } \\
\text { Drug to lipid ratio according to active } \\
\text { collagenase }\end{array}$ & 0.069 \\
\hline
\end{tabular}


Figure S1: (A) NanoSight, 100-nm PEGylated nanoparticle measurements. We measured the liposomes concentration by diluting the particles by $1: 10^{6}$ (vol ratio) within PBS buffer. $1.31 \mathrm{e}^{15}$ particles/ml were measured. (B) Stability of nanoparticle size in DLS. Red line- fresh collagenase liposome sample, green line- one month old sample of collagenase liposomes kept at $4^{\circ} \mathrm{C}$. (C) Zeta potential measurement: Black line- PBS, red line- empty liposomes, green line- collagenase liposomes encapsulating starting concentration of $2 \mathrm{mg} / \mathrm{ml}$ collagenase, blue line- collagenase liposomes encapsulating starting concentration of $4 \mathrm{mg} / \mathrm{ml}$ collagenase. (D) Drug to lipid ratio of collagenase liposomes. Lipid quantity was determined by Stewart assay, protein quantity was determined by Fluorescamine assay after disruption using 1\% triton-x100 in PBS. The mixture was placed in an Eppendorf shaker at $55^{\circ} \mathrm{C}$ at $300 \mathrm{rpm}$ for 15 minutes to dissociate the liposomes. The mixture was centrifuged for 10 minutes at $12,000 \mathrm{rpm}$ at $4^{\circ} \mathrm{C}$. The liposome-free supernatant was collected and centrifuged again for 10 minutes at $12,000 \mathrm{rpm}$ at $4^{\circ} \mathrm{C}$ and then Fluorescamine fluorescence was determined. Protein activity was determined following 1-hour incubation at $37^{\circ} \mathrm{C}$ by Enzcheck assay.

Table S1: Calculation steps of nanoparticle biodistribution described in Figure 1N.

\begin{tabular}{|c|c|c|}
\hline $\begin{array}{c}\text { Quantification method } \\
\begin{array}{c}\text { NanoSight } \\
\text { measurement } \\
\text { Figure S1A }\end{array}\end{array}$ & $\begin{array}{c}\text { Particle concentration } \\
\text { (particles/ml) }\end{array}$ & Biodistribution steps \\
\hline $\begin{array}{c}\text { Non-invasive Intra-vital } \\
\text { microscopy } \\
\text { Figure 1K, L }\end{array}$ & $1.3 \times 10^{13}$ & Only 1\% reached the pancreas \\
\hline $\begin{array}{c}\text { Quantitative } \\
\text { histological analysis } \\
\text { Figure 1M, N }\end{array}$ & $3.9 \times 10^{11}$ & $\begin{array}{c}\text { Only 3\% accumulated in the tumor } \\
\text { area * explained by the figure } \\
\text { attached below. }\end{array}$ \\
\hline
\end{tabular}




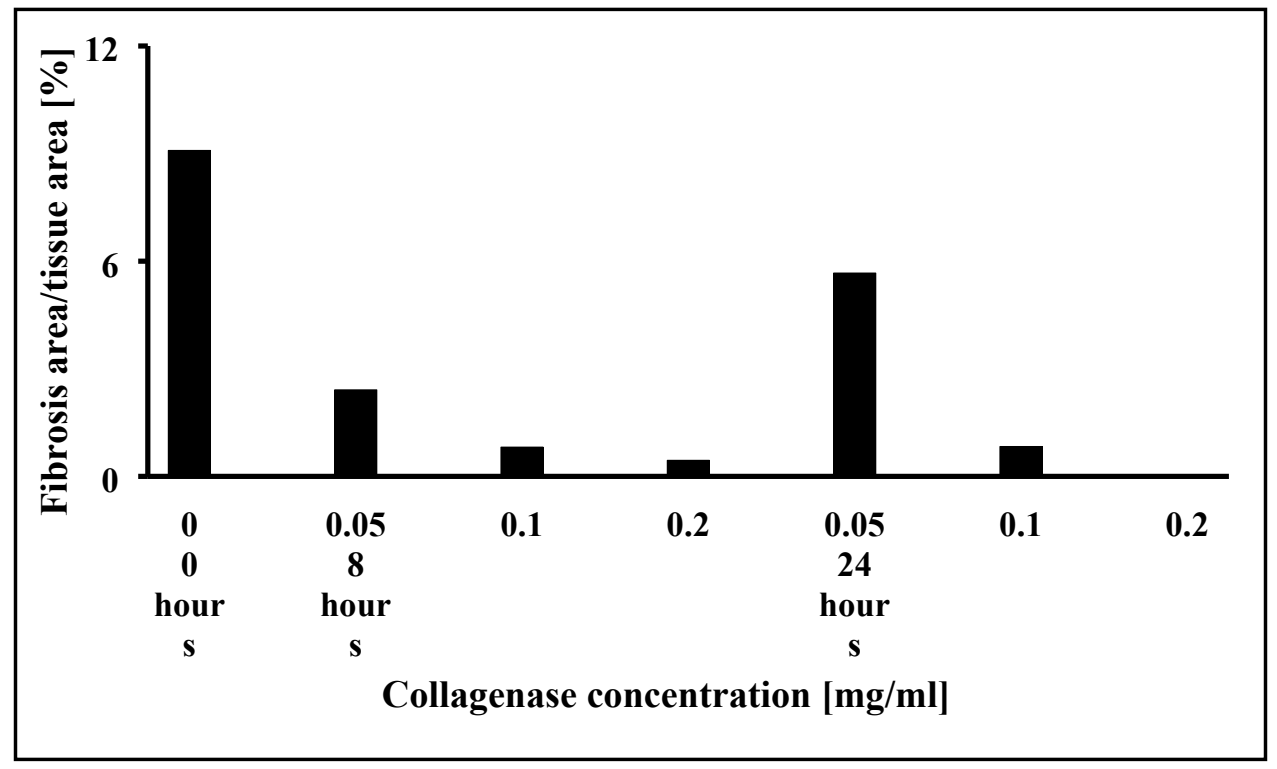

Figure S2: Three collagenase concentrations $(0.05,0.1$ and $0.2 \mathrm{mg} / \mathrm{ml})$ were tested over two times intervals (8 and $\mathbf{2 4}$ hours). The highest levels of collagen were measured within the PDAC not treated group $=9.08 \%$ while the lowest levels were measured among the $0.2 \mathrm{mg} / \mathrm{ml}$ treated groups $=0.44,0.006 \% 8$ hours and 24 hours respectively. The levels of collagen within the $0.05 \mathrm{mg} / \mathrm{ml}$ groups $=2.41,5.66 \% 8$ hours and 24 hours respectively were lower than the PDAC not treated group but higher than the $0.1 \mathrm{mg} / \mathrm{ml}$ group $0.81,0.83 \% 8$ hours and 24 hours respectively. No differences between the 8 hours and 24 hours groups were observed, a fact that might be contributed to the free enzyme deactivation time in biological buffers (Figure. 1E). ( $n=2$ replicates). 

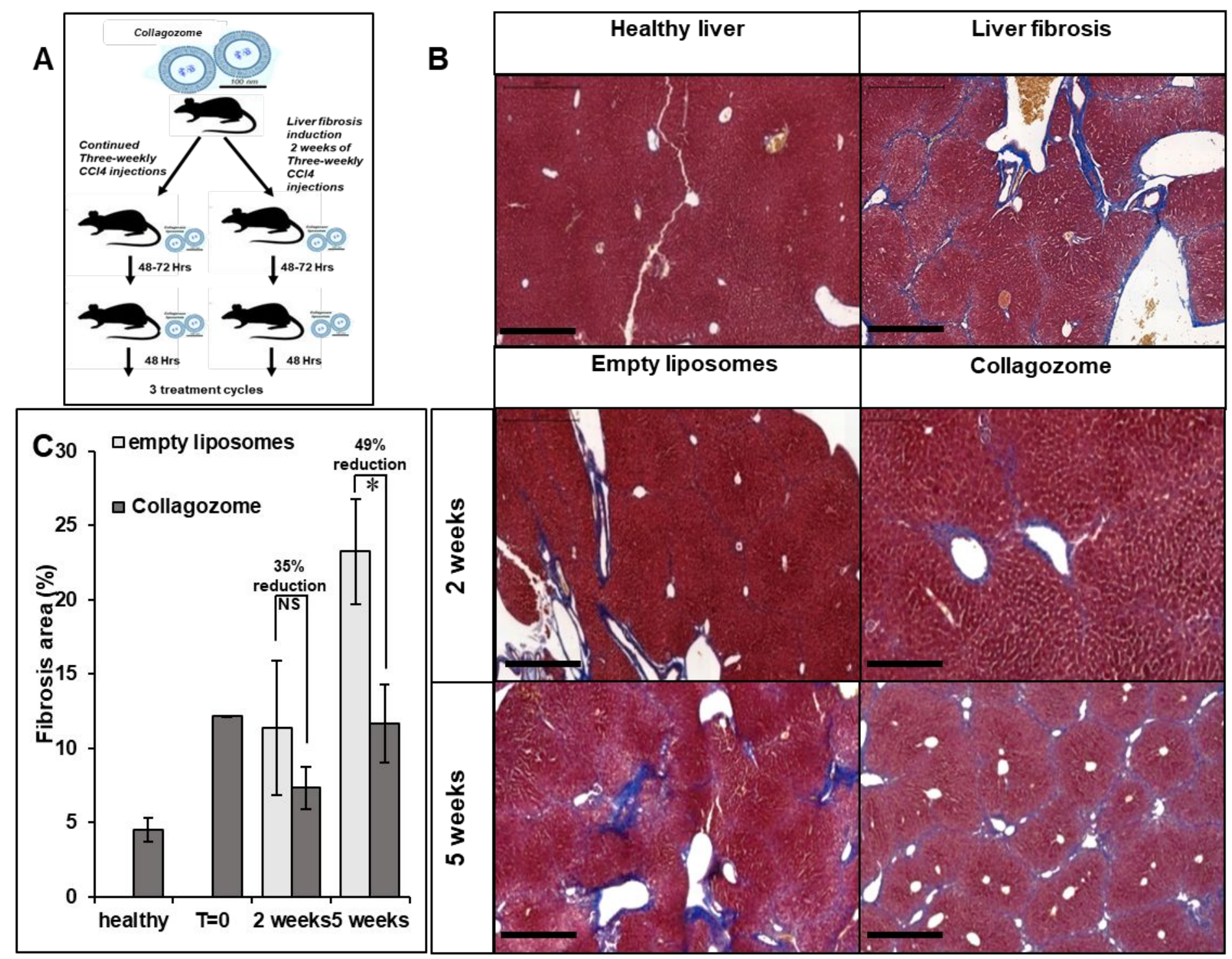

SFigure 3 Collagozome reduce collagen quantity in liver fibrosis

A schematic representation of the treatment protocol (A)mice were injected triweekly with $2 \mathrm{ml} / \mathrm{Kg} \mathrm{CCl} 4$ for 2 weeks. Two groups were continued to be injected with 1 $\mathrm{ml} / \mathrm{Kg}$ throughout liposomal treatment while two groups were only injected with treatment. Mice were tri-weekly intravenously injected with either $200 \mu$ l of collagozome or $200 \mu$ l of empty liposomes for 3 weeks. (B) Quantification of Masson's Trichrome staining was done by Image J. Five sections were quantified for \% collagen in area in at least three mice of the same treatment $(C)$ Liver sections were stained for collagen with Masson's Trichrome in mice liver tissue. Scale bar $=200 \mu \mathrm{m}$.

*indicates $p$-value $<0.05$ according to a student's t-test with two-tailed distribution with unequal variance. $P$-value presented was calculated between specified bars according to a student's t-test with a two-tailed distribution with heterodetic unequal variance for multiple comparisons. 
A
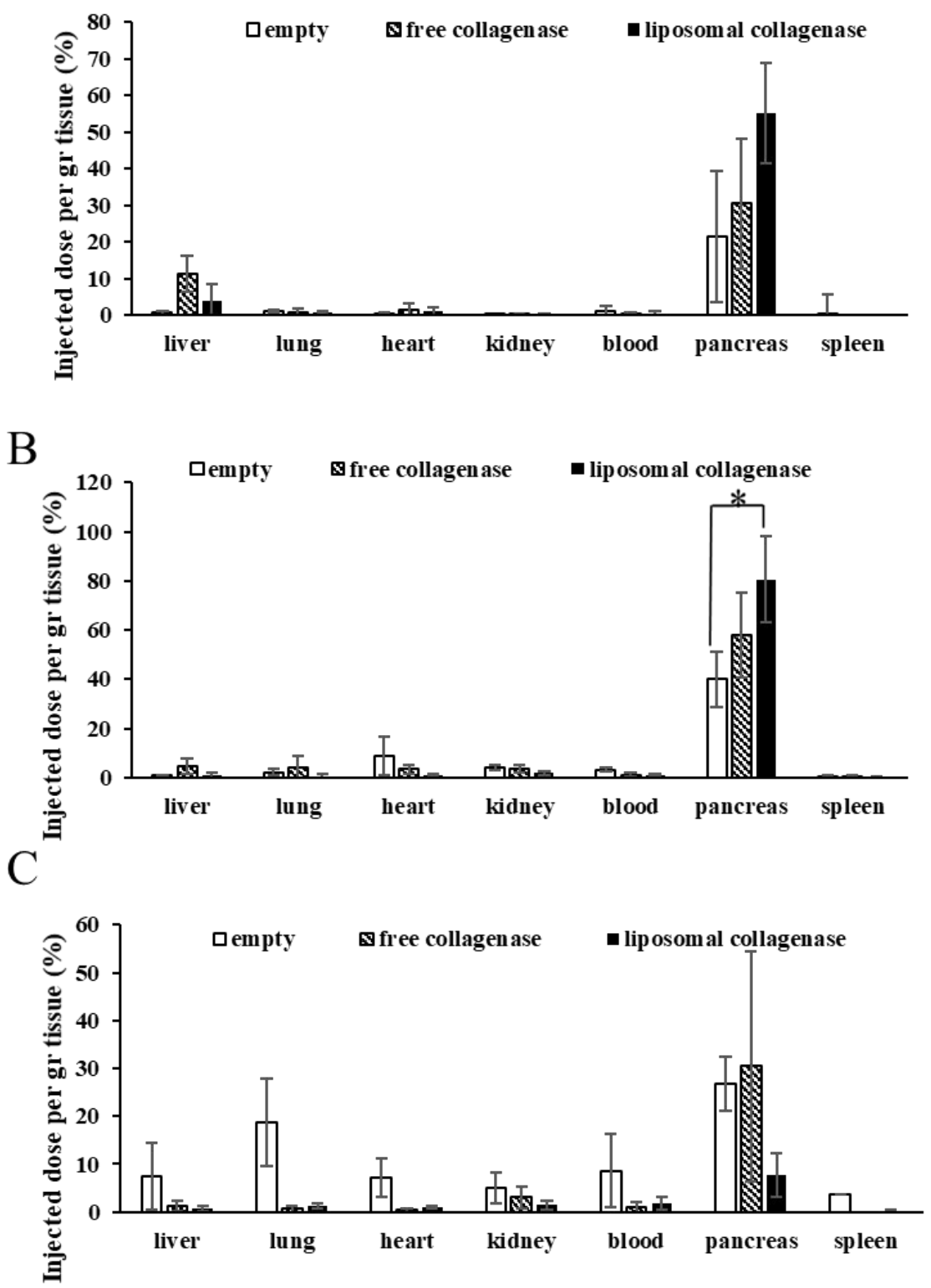

Figure S4: Biodistribution of gold nanoparticles to various organs was enhanced in healthy mice following collagenase treatment Mice were administered with either 100-nm liposomes loaded with collagenase, empty liposomes or free collagenase, day after day, followed by a single dose of $5-\mathrm{nm}$ (A), 20-nm (B) or 100-nm (C) gold nanoparticles $(100 \mu \mathrm{l}, 5 \mathrm{mg} / \mathrm{ml}) \quad(n=5$ biological replicates). The amount of gold nanoparticles that reached the various organs of PDAC mice after an intravenous administration was quantified using elemental analysis. ${ }^{*}$ indicates $p$-value $<0.05$ according to a student's t-test with two-tailed distribution with unequal variance. 
A

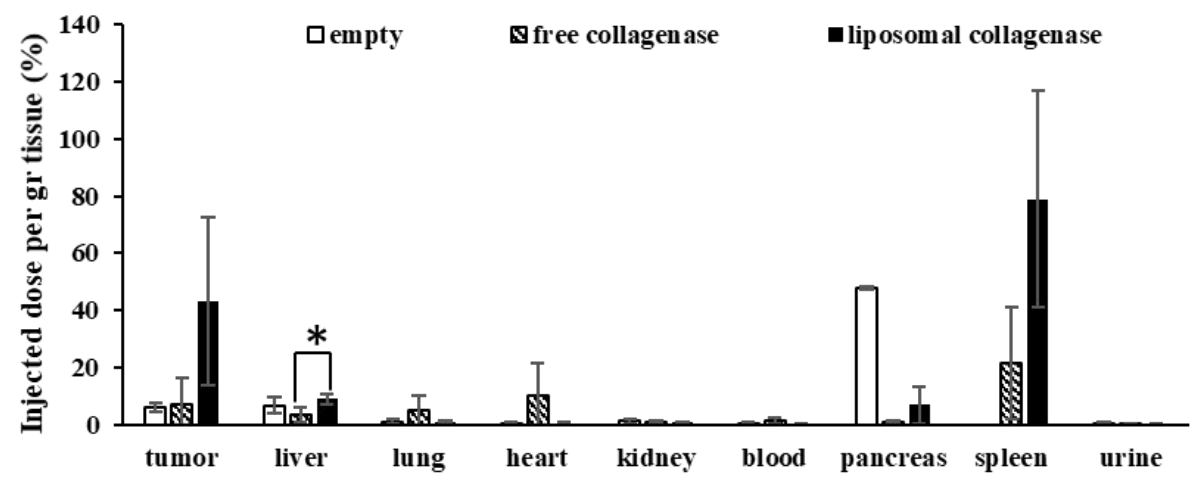

$\mathrm{B}$

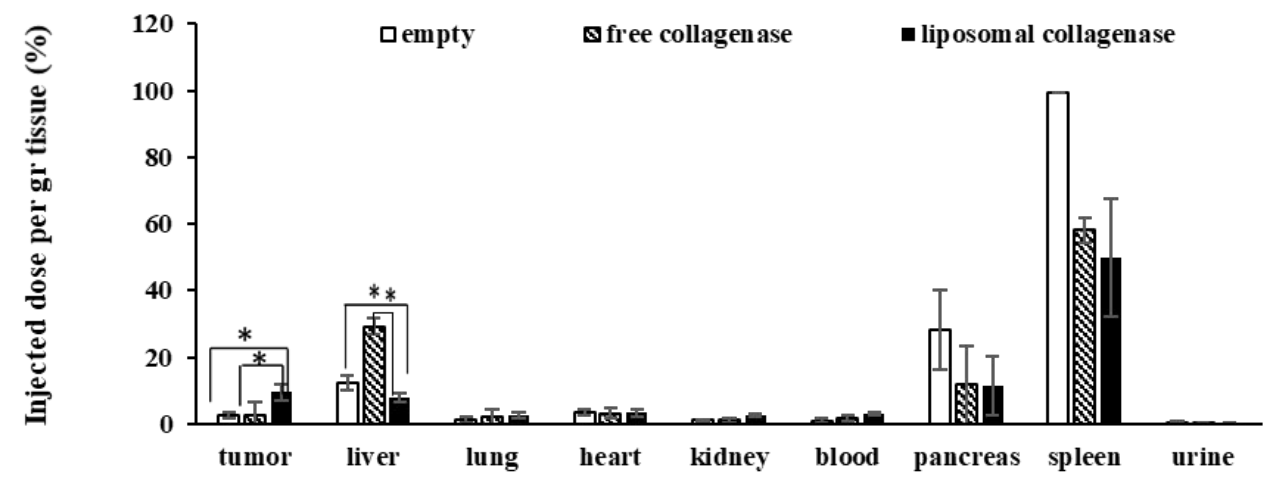

Figure S5: Biodistribution of gold nanoparticles to various organs was enhanced in PDAC tumor baring mice following collagenase treatment PDAC Mice were administered with either 100-nm liposomes loaded with collagenase, empty liposomes or free collagenase, day after day, followed by a single dose of $20-\mathbf{n m}(A)$ or $100-\mathbf{n m}(B)$ gold nanoparticles $(100 \mu \mathrm{l}, 5 \mathrm{mg} / \mathrm{ml})(\mathrm{n}=5$ biological replicates). The amount of gold nanoparticles that reached the various organs of PDAC mice after an intravenous administration was quantified using elemental analysis.

*indicates $p$-value $<0.05$ according to a student's t-test with two-tailed distribution with unequal variance. 


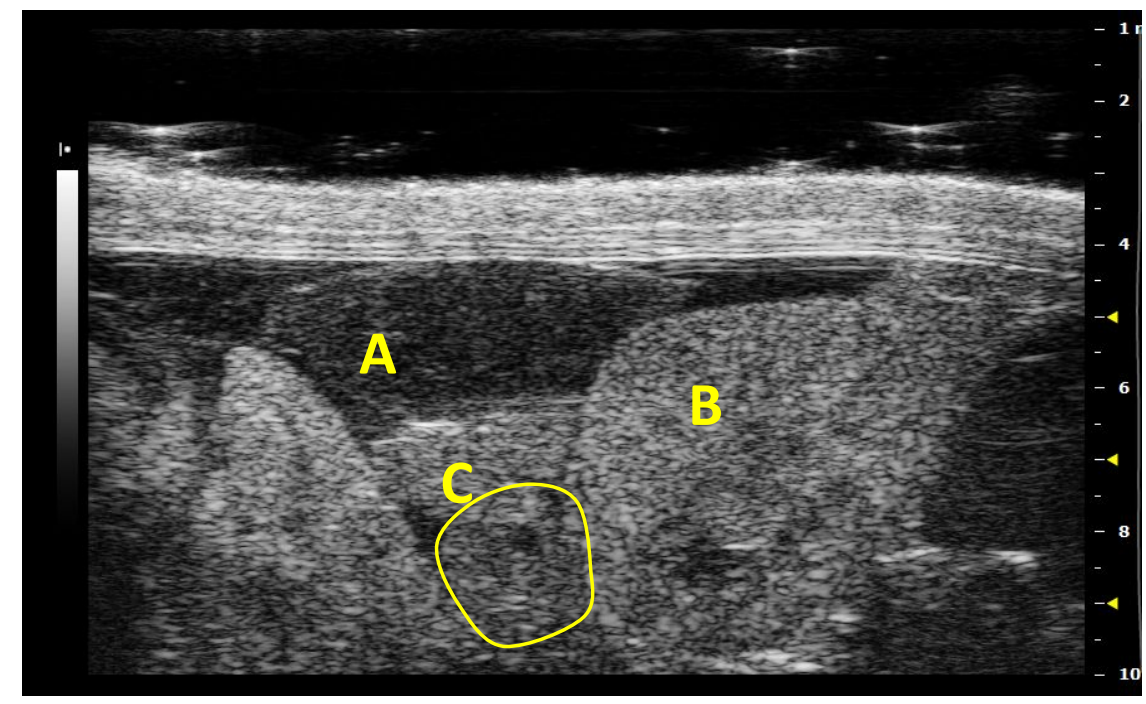

Figure S6: Measurement of pancreatic tumors in vivo was done with microultrasound PDAC Mice were anesthetized and imaged via $22-55 \mathrm{MHz}$ (MS550D) array transducer to evaluate tumor size before treatment. (A) spleen, (B) kidney, (C) pancreas with tumor.

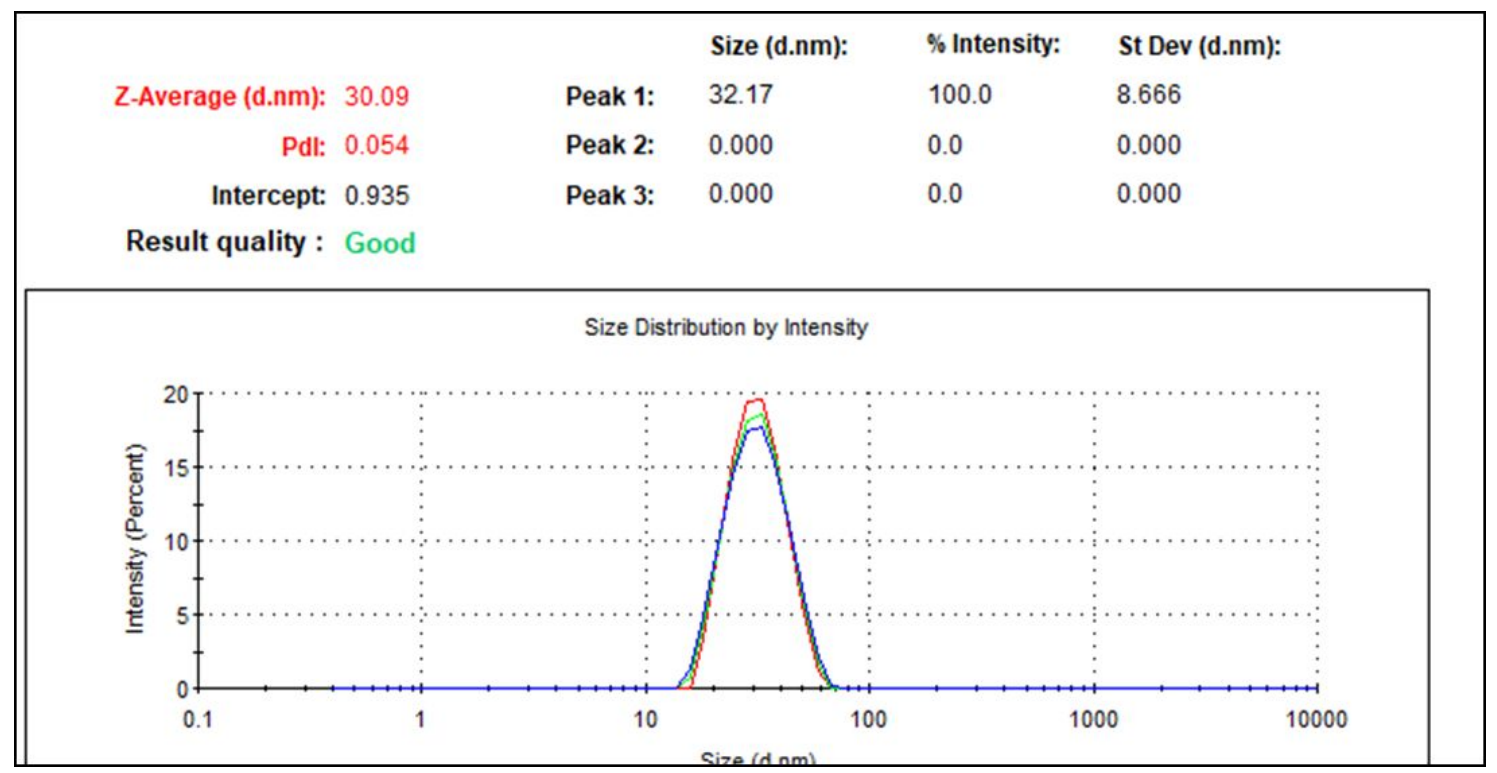

Figure S7: DLS measurement of paclitaxel micelles size average size of 30-nm. 
